\title{
Giant Cystic Craniopharyngioma: Case Report
}

\author{
DWIGHT PARKINSON, and MICHAEL WEST
}

SUMMARY: This is a report of a giant cystic craniopharyngioma which escaped diagnosis for nine years in spite of seemingly thorough neuroradiological investigation, prior to the advent of the $C T$ scan.

RESUME: Nous présentons l'examen d'un craniopharygiome kystique géant qui n'avait pas été diagnostiqué pendant 9 ans malgré une investigation neuroradiologique complète, et ce jusqu'à l'emploi de la tomodensitométrie cérébrale.

From the Department of Surgery, Neurological Surgery, Faculty of Medicine, University of Manitoba, Winnipeg, Manitoba, Canada.

Reprint requests to: Dr. Dwight Parkinson, Section of Neurosurgery, Faculty of Medicine, University of Manitoba, S-105, 770 Bannatyne Avenue, Winnipeg, Manitoba. R3E 0W3 Canada.

\section{INTRODUCTION}

In cases of craniopharyngioma, establishing a diagnosis is not usually a major problem once suspicion of intracranial pathology is aroused. This is the report of an unusually large cystic craniopharyngioma which over nine years progressed to the point of hemiplegia, hemianopia, and stupor without a diagnosis, in spite of seemingly thorough neuroradiological investigation and treatment for hydrocephalus.

\section{CASE REPORT}

In 1968, a thin right handed 9-yearold male of normal intelligence, stature, and head circumference was seen because of a two-year history of progressive left hemiparesis and occasional generalized headache. Skull x-rays, carotid angiography, pneumoencephalography, and electroencephalogy were all read as normal.

The patient was seen again in 1973 because of decreased level of consciousness, increasing left hemiparesis, a left homonymous hemianopsia, and papilledema. Stature and gonadal development were normal. Skull $\mathrm{x}$-rays were again normal. Angiography demonstrated a wide sweep of the pericallosal artery with a lateral displacement of the middle cerebral vessels and a downward displacement of the posterior cerebral without any mid-line shift (Figs. la \& b).

Ventriculography confirmed the presence of symmetrical dilatation of the supratentorial ventricular system but demonstrated no evidence of a space occupying lesion. Figs. $2 a$ \& b.

A diagnosis of communicating hydrocephalus was made. Following the establishment of ventriculoperitoneal shunt, he immediately regained normal consciousness, while the hemiparesis and hemianopsia remained unchanged. He was discharged one week post-operatively.

He was readmitted in 1977, drowsy, nauseated, and vomiting, with normal development and marked left hemiparesis, a left homonymous hemianopsia, and pale optic discs. The shunt was blocked at the proximal end. At operation, while attempting to canulate the right lateral ventricle, golden brown fluid containing shimmering crystals was encountered. Eighty-five ccs were withdrawn and partially replaced with air and 3ccs of Myodil. Subsequent x-rays revealed a spherical cavity measuring $8.3 \times 6.7 \times$ $7.5 \mathrm{~cm}$. (Figs. 3a \& b).

A Rickham reservoir was inserted on January 25,1978 , and 300 ccs of similar fluid were removed. Microscopic examination revealed macrophages and cells of epithelial origin in addition to the cholesterol crystals consistent with fluid from a craniopharyngioma.

He was discharged and followed as an out-patient. A few drops of fluid were recovered from the reservoir at the first visit and none since. Serial $\mathrm{x}$ rays and $C T$ scans revealed shrinkage of the cavity to a diameter of about 1 $\mathrm{cm}$ within two weeks and no enlargement in the following 18 months (Figs. 4a \& b, 5).

The patient is in University with considerable improvement in his hemiparesis and no change in his hemianopsia. He has a normal endocrine status, mentality, initiative, and drive.

\section{DISCUSSION}

It is most unusual that a mass of such dimensions as to produce hemiplegia, hemianopsia, eventual hydrocephalus and raised intracranial pressure should escape detection by the usual neuroradiological procedures. Plain skull films are stated to be positive in $94 \%$ of the craniophary- 
ngiomas (McKenzie and Sossman, 1924; Taveras and Wood, 1964). Ventriculography is reported as almost always abnormal (Matson, 1969). Computerized tomography was not available at the time of the patient's original assessment. However, an air study is thought to be more accurate than $\mathrm{CT}$ scanning in the diagnosis of craniopharyngioma (Volpe et al., 1978). The typical upward displacement of the proximal anterior cerebral artery on the AP projection associated with a suprasellar mass may not occur (Hunt et al., 1973). Even a large mass may escape on a "stalk" above the vessels at the base of the brain and progress to obstruct the foramen of Monro without elevating the anterior cerebral artery (Banna, 1976; Gado and Bull, 1971; Matson, 1969; Taveras and Wood, 1964). We could find no report in which neuroradiological studies were negative in the presence of such a large tumor.
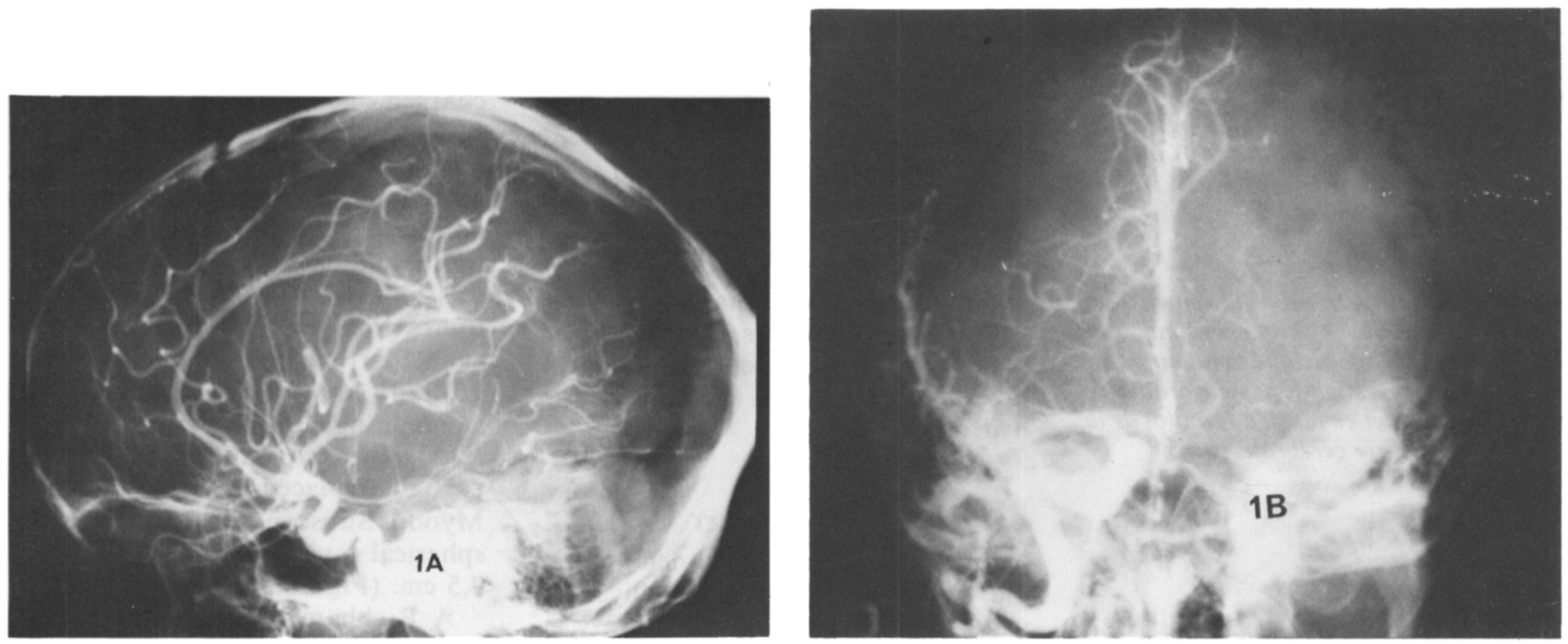

Figure lA June, 1973 - Right carotid angiogram. Note sweep of anterior cerebral artery and curved downward displacement of the posterior cerebral artery. The coronal suture is widened.

Figure $1 B$ - AP view demonstrating lateral displacement of the middle cerebral vessels. There is no displacement of the horizontal segment of the anterior cerebral.
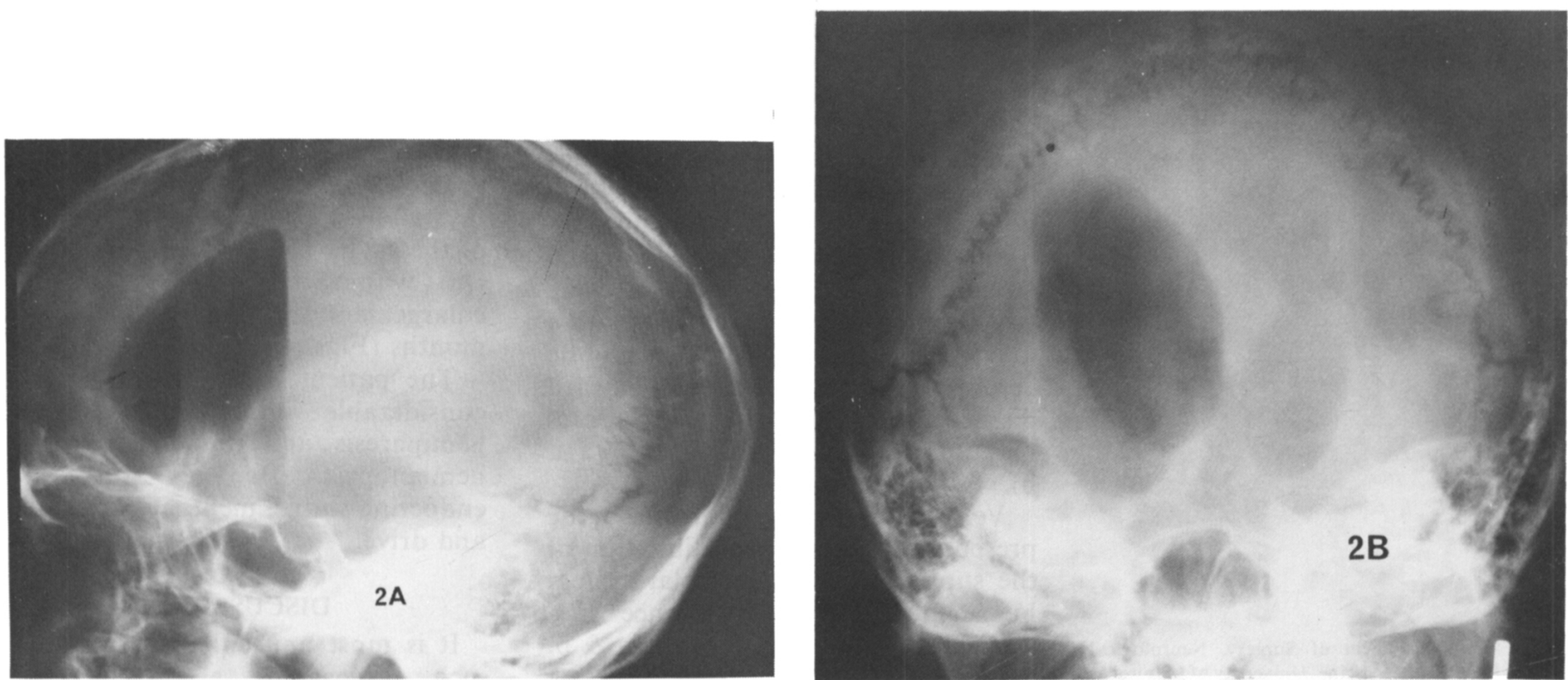

Figure $2 A \& B$ June, 1973 - Ventriculogram showing a marked symmetrical supratentorial ventricular enlargement confirming the angiographic findings. There is no evidence of a suprasellar mass. The minimal apparent shift was interpreted as due to slight rotation and unequal filling of the lateral ventricles. Additional positions and completed studies led to a diagnosis of a communicating hydrocephalus. 

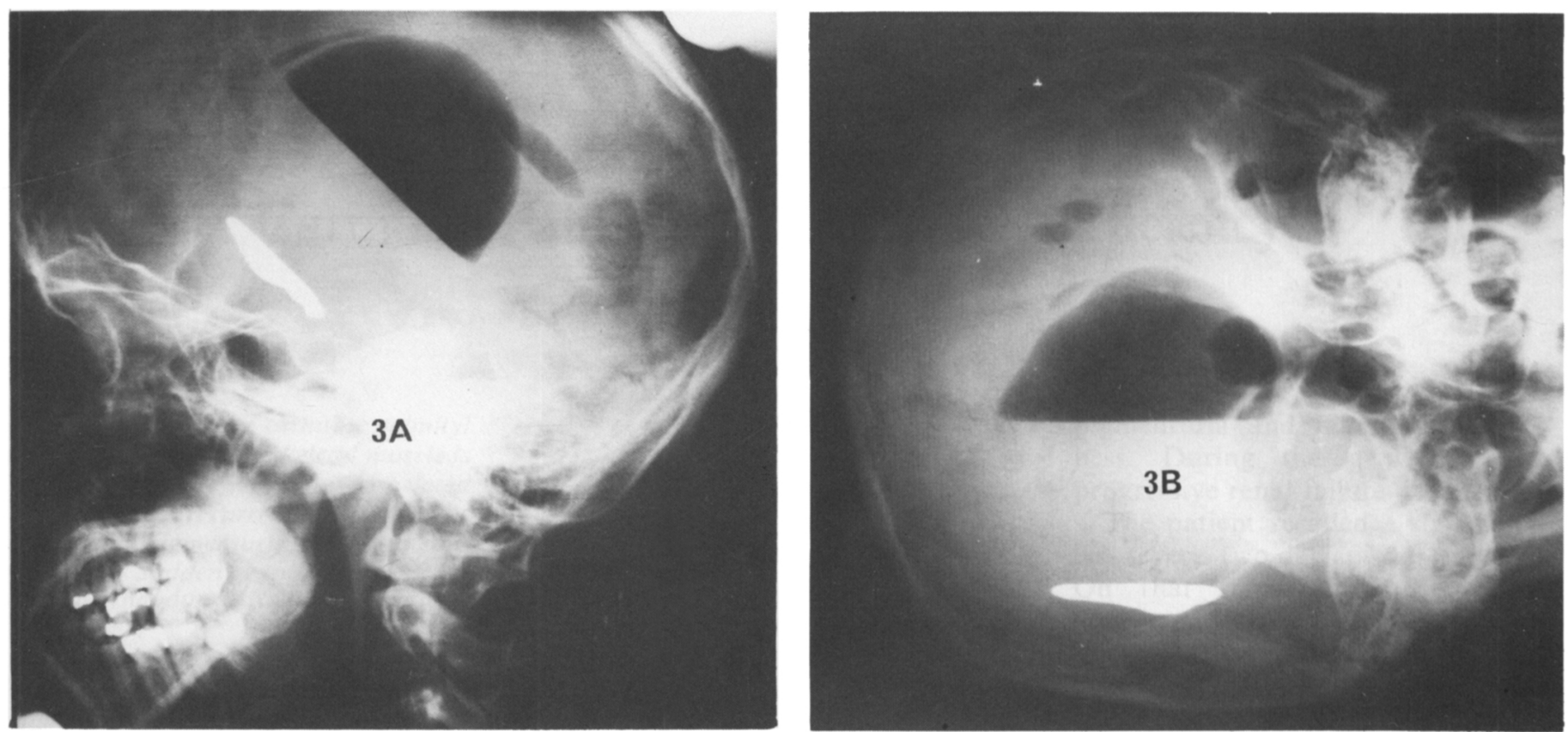

Figure 3A January, 1977 - Postoperative films with $85 \mathrm{ml}$. of air and $3 \mathrm{ml}$. of Myodil in the cyst. The right lateral ventricle is seen as a slender crescent of air superior to the cyst which is outlined by air above and Myodil below.

Figure $3 B-$ Crosstable lateral, right side down, outlining the left and right borders of the cyst again with the slender segment of the ventricle seen above the cyst.

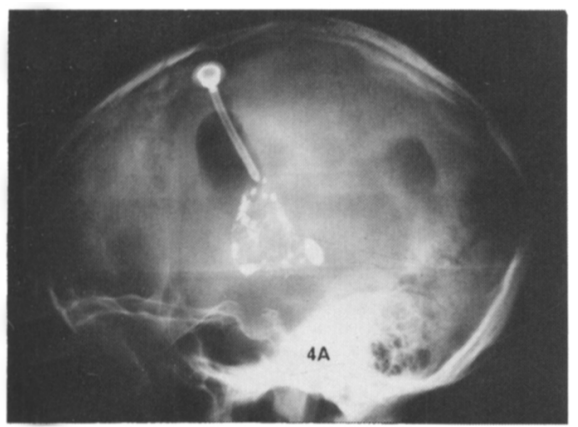

Figure 4A February, 1977 - Films taken 2 weeks later 'after aspiration via the Rickham Reservoir showing the marked reduction in the cyst size.

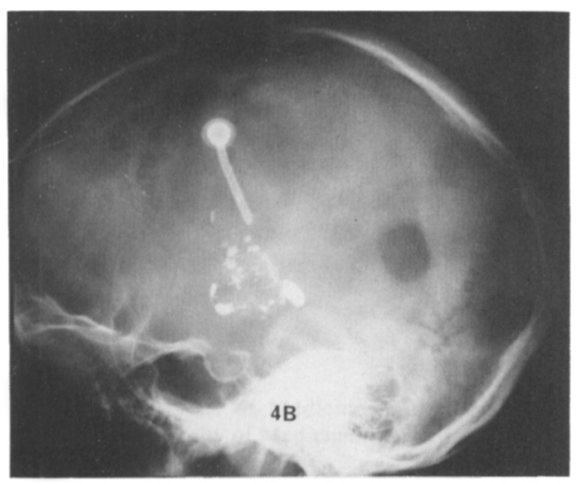

Figure $4 B-$ Films 3 weeks later.

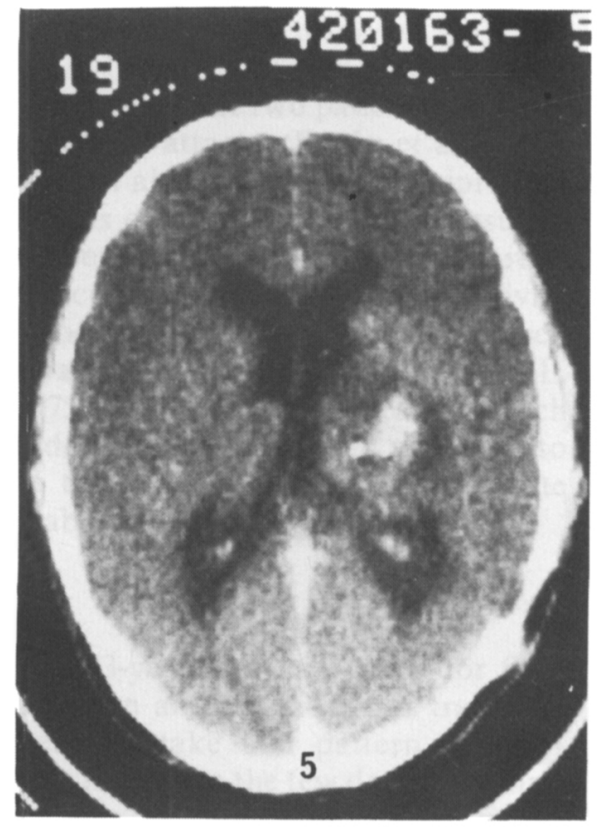

Figure 5 January, 1978 - CT scan 11 months following aspiration showing the small residual cavity containing the contrast material in the region of the right internal capsule. The ventricular system is mid-line and moderately dilated. CT scan 18 months postoperatively was identical.

\section{REFERENCES}

BANNA, M. (1976). Craniopharyngioma. Br. J. Radiol. 49: 206-223.

GADO, M., BULL, J. W. D. (1971). The carotid angiogram in suprasellar masses. Neuroradiology. 2; 136-153.

HUNT, W. E., SAYERS, M. P., YASHOR, D. (1973). Tumors of the sellar and parasellar area, in Youmans, J. R. (ed.): Neurological Surgery. Philadelphia. Saunders, Vol. 3, pp 1412-1413.

MATSON, D. D. (1969). Craniopharyngioma in MATSON, D. D.: Neurosurgery of infancy and childhood, ed. 2. Springfield. Charles C. Thomas, pp. 544-574.

McKENZIE, K. G., SOSSMAN, M. C. (1924). The roentgenological diagnosis of craniopharyngeal pouch tumors. Amer. J. Roentgenol. 11: 171-176.

TAVERAS, J. M., WOOD, E. H. (1964) Diagnostic Neuroradiology, ed. 1, Baltimore: Williams and Wilkins, pp. 648-649.

VOLPE, B. T., FOLEY, K. M., and HOWIESON, J. (1978). Normal CAT scans in Craniopharyngioma. Ann. Neurol. 3: 87-89. 